cadmium films-were generally confirmed; but, in addition, unusual effects were noticed during the oxidation, by heating, of tin films on a glass substrate. A stage was reached, in certain cases, when the film had become transparent but shortly afterwards acquired appreciable electrical conductivity.

This observation is the basis of a new process proposed for the preparation of transparent conducting films. In it, a sputtered partially oxidized tin film on glass is subjected to suitable heat treatment. The initial film must be amorphous, it seems, while the final product after heating gives the electron reflexion pattern of stannic oxide. It is hard, adherent, and chemically as resistant as ordinary stannic oxide. Its optical transmission is in the region of 75 per cent. Resistance values of a thousand ohms, or rather less, between opposite edges of any square area, have been reached by this method, but still further reduction of this figure is expected as a result of work in progress.

The manufacture is as yet assured only on the labaratory scale. Application of the process to some commercial uses therefore awaits further development; but the present product is obviously suitable for a number of practical applications such as for anti-static windows in sensitive electrical instruments. It may also prove suitable for the manufacture of robust resistors, where the large surface area of the film should permit of an unusually large powerdissipation without undue rise in temperature.

Unlike the American process, the modified sputtering process used in making the tin oxide films is adaptable to a wide variety of substances, and other films now under study at the National Physical Laboratory show a great improvement on the American product in respect of electrical conductivity at a similar transparency. Some of their other properties remain still to be tested, and so it is too early as yet to forecast the precise field of application for these newer films.

1 Ann. Phys. Leipzig, 22, 749 (1907).

\section{RESEARCH AND INVENTION IN THE UNITED STATES}

\section{REPORT OF THE NATIONAL SCIENCE FOUNDATION}

$\mathrm{T}$

HE establishment of the National Science Foundation in the United States by Act of Congress on May 10, 1950, broke new ground, comparable possibly with the establishment in Great Britain of the Advisory Council for Scientific and Industrial Research thirty-five years earlier. Some of the functions of the Foundation, however, are more in the field of those of the Advisory Council on Scientific Policy and the Defence Research Policy Committee set up in 1947. The Foundation, for example, is authorized and directed to develop a national policy for the promotion of basic research and education in the sciences; to support basic scientific research and to appraise the impact of research upon industrial development and the general welfare; and, at the request of the Secretary of Defence, to support specific defence research activities. Other functions, such as awarding scholarships and graduate fellowships in the sciences, fostering the exchange of scientific information, evaluating scientific research undertaken by Federal agencies, correlating the Foundation's research programmes with other such programmes and co-operating in international scientific research activities, follow the pattern of the activities of the Department of Scientific and Industrial Research or its Advisory Council in Britain; but the Foundation is also responsible for maintaining a register of scientific and technical personnel, and for serving as a clearing house for such personnel, a task which in Britain is in the hands of the Ministry of Labour and National Service.

The responsibility for disbursing Federal expenditure in this way is vested in a National Science Board of twenty-four persons eminent in science, medicine, engineering, agriculture, education and public affairs, appointed by the President of the United States and confirmed by the Senate; and the chief executive officer, the Director of the Foundation, is similarly appointed by the President and confirmed by the Senate. The first annual report of the Foundation*, covering the year 1950-51, is, as Dr. J. B. Conant, the first chairman of the National Science Board, emphasizes in a foreword, essentially a record of progress in formulating plans, and it will be several years before concrete achievements can be listed. Even in the field of applied science, research is in the nature of a long-term investment, while in the basic sciences there may be an even more considerable time-lag. Dr. Conant suggests, as a personal point of view, that it would be wise to discard the terms 'applied research' and 'fundamental research' and substitute 'programmatic research' and 'uncommitted research' as making clearer the difference between these two possible forms of research. A like suggestion has been made elsewhere, and Dr. Conant insists that in the United States it is the uncommitted investigator who is in the greatest need of public support, and that besides more financial support he requires wider public recognition. One purpose of the National Science Foundation is to assist the United States to produce its proper share of such scientific pioneers, and to secure that provision is made for the educational and research facilities which will assist the development of such men. Much of this first annual report is occupied by an able exposition of the nature of fundamental research and the importance of prosecuting it adequately, even in times of national emergency. Examples are cited from electronics, biology and medicine, including penicillin, to illustrate the need for sustained support. This part of the report, with its emphasis in conclusion on the dwindling time-lag, seems admirably argued to counteract the lack of knowledge which must have been responsible for the sudden slashing of the Foundation's appropriation early last autumn.

The immediate problem before the Foundation is, in fact, the relation of the present emergency to the support of basic research. The Foundation is planning its programme from the point of view that, since the degree and duration of the present emergency are uncertain, the United States must, with all dispatch, put itself into "operational readiness" and take the necessary steps to maintain itself in this state of readiness for an extended period, perhaps for many years. For science, this means that urgent military uses of science would be expedited where such uses could be put into practice in a short time, such as two or three years. This would involve careful selection * First Annual Report of the National Science Foundation, 1950-51.
Pp. ix +31 . (Washington, D.C.: Government Printing Office, 1952.)
20 cents. 
from the point of view of feasibility and of high priority. It equally involves the United States remaining in scientific readiness over a long period of years, with the utmost effort to strengthen its scientific progress and maintain that strength at the highest possible level.

It is at this point that the programme of basic research to be supported by the National Science Foundation can be most effective, and the report then details the questions to be answered in developing and formulating a national science policy. Much of this ground has been covered in recent years by the Steelman report, "Science and Public Policy", and the earlier Vannevar Bush report, "Sciencethe Endless Frontier". Among its first tasks the National Science Foundation plans to make a thorough review of the present national pattern of research and development. It will seek current answers to such questions as what is the total financial support now being provided for scientific research and its distribution among government projects, industry and educational institutions: what financial support can and should be provided, and what is the most desirable distribution. It will also be necessary to determine the division of research effort among the various natural sciences, and also the areas which need greater or less emphasis.

Estimates quoted in the report indicate that the United States is at present spending about 2,500 million dollars a year on research and development, of which 60-70 per cent comes from the Federal Government and 5 per cent from the universities. While industry supplies between 25 and 35 per cent of the funds, nearly two-thirds of the expenditure goes into industrial laboratories and facilities, slightly more than 10 per cent being in the universities. About onefifth of the university research effort is in physics, and nearly one-half in the three areas of chemistry, physics and electronics. Another 25 per cent of the defence research work is in aeronautical and electrical engineering, mathematics and the terrestrial sciences. Continued pressure upon the universities for defence research without compensating support for basic research could, in the opinion of the Engineering College Research Council, which has examined the situation, easily upset the present balance.

The Foundation proposes to support basic research upon as broad a geographical and institutional basis as possible, as well as to examine the effect of Federal research programmes on the financial stability of universities. It is giving attention to the need for accurate current information on scientific man-power both for sound planning and for mobilization purposes. At present, it is estimated that about 130,000 engineers and scientific men in the United States are engaged in research and development, about 55 per cent being in industrial laboratories, 25 per cent in universities and non-profit-making institutions and the remaining 20 per cent in Federal and State institutions. The military research budget alone requires the services of 54,000 research scientists and engineers, or 47 per cent of the total in the United States. The projected plans for 1952 of the Defense Department, the Atomic Energy Commission and the National Advisory Committee for Aeronautics may take up to 70 per cent of the research man-power.

Such a position emphasizes the importance of the training programme in science which the National Science Foundation proposes to plan, as well as the necessity of securing the wisest and most effective use of the available supply of trained personnel. It is apparent that the Foundation is being led to engage on numerous activities which in Great Britain have for some time come within the purview of the Lord President of the Council or the Advisory Council on Soientific Policy, including the question of the dissemination of scientific information by existing means or by new techniques. Its future reports should be useful as well as interesting to those in other countries who have to confront similar problems, and may well contribute something to that mutual understanding and to the formulation of a common policy in matters of mutual interest for which Dr. Conant pleaded so eloquently and cogently during his recent visit to London. Meanwhile, this first report seems well fitted for winning fuller support in the United States, both from the general public and from scientific workers themselves, for a larger measure of central government endowment of research.

\section{CENTIMETRE-WAVE RADIO LINKS}

A $T$ a meeting of the Radio Section of the InstituA tion of Electrical Engineers on April 9, three papers were presented describing the theory, design and development of radio links which are now in general use for multi-channel telephony and television. The work described was carried out by a large group of engineers in the Telecommunication Laboratories of Standard Telephones and Cables, Ltd.

The first paper, by Dr. A. T. Starr and T. H. Walker, entitled "Microwave Radio Links", dealt with the general theory and design of such links as transmission systems. Following provisional allocation made at an international convention, the frequencies selected for study and development are about 4,000 Mc./s. (wave-length $7.5 \mathrm{~cm}$.) for fixed links, and 5,000-6,000 Mc./s. (5-6 cm.) for mobile radio links. The paper deals with questions of propagation and atmospheric phenomena in so far as they affect the design, and with the conditions it is necessary to meet in order to reduce thermal and intermodulation noise to a minimum. The special problems of a television link are discussed.

The second paper, on "Circuit Technique in Frequency-modulated Microwave Links", by $H$. Grayson, T. S. McLeod and R. A. G. Dunkley, describes in more detail the circuit problems involved in wide-band communication links, and the principles of design of the amplifying, modulating and demodulating circuits involved. Special attention is given to the need for automatic frequency-control throughout the system. In the third paper, entitled "Microwave 'Techniques for Communication Links", G. King, L. Lewin, J. Lipinski and J. B. Setchfield describe theoretical and practical work involved in the development of radio links to work in the frequency range $3,600-4,200 \mathrm{Mc} . / \mathrm{s} .(7 \cdot 15-8 \cdot 33 \mathrm{~cm}$.$) .$ Special attention has been given to the problem of matching components of the system over the broad frequency band used, and this included the matching of waveguide sections as well as the feeding arrangements to the parabolic mirror type of antenna system used in this work. This paper contains a section on the measuring technique involved, with a description of a precision signal-generator developed for use at the frequencies mentioned. 